\title{
POTABILIDADE DA ÁGUA DE CACIMBAS: ESTUDO DE CASO EM UM DISTRITO DA CIDADE DE BARRO, CEARÁ
}

\author{
S. R. Souza ${ }^{1}$, E. O. Sousa ${ }^{1 *}$
}

BIOENG

\section{${ }^{1}$ Faculdade de Tecnologia do Cariri-FATEC, Juazeiro do Norte, CE, Brasil}

Article history: Received 07 June 2020; Received in revised form 21 September 2020; Accepted 23 September 2020; Available online 30 December 2020.

\begin{abstract}
RESUMO
Nesse sentido, o presente trabalho buscou analisar a qualidade físico-química e microbiológica da água proveniente de cacimbas na zona rural do distrito de Iara, cidade de Barro, Ceará. As amostras de água foram coletadas diretamente nas cacimbas em fracos esterilizados, depois foram armazenadas em caixas térmicas com gelo para conservação e transportadas para análises em laboratório. Foram realizadas análises físico-químicas para determinação da turbidez, condutividade elétrica, dureza total, cloretos, nitrogênio amoniacal, nitrato, nitrito, $\mathrm{pH}$, alumínio, ferro total, sólidos totais dissolvidos e manganês, e análises microbiológicas para determinação de coliformes totais e Escherichia coli. Os resultados mostraram que a maioria das amostras de água proveniente das cacimbas apresentaram qualidade em relação aos parâmetros físico-químicos, mas algumas mostraram alterações em relação a dureza, e aos teores de nitrato e ferro. Todas as amostras apresentaram contaminação microbiológica por coliformes totais e somente uma não teve contaminação por E. coli. Os dados reforçam a questão da susceptibilidade das cacimbas a vários fatores de contaminação e a necessidade de maiores medidas para se rever hábitos da população que provocam a contaminação de cacimbas.
\end{abstract}

Palavras-chave: Abastecimento de água. Qualidade da água. Análises físico-química e microbiológica.

\section{WATER POTABILITY OF CACIMBAS: CASE STUDY IN A DISTRICT OF THE CITY OF BARRO, CEARÁ}

\begin{abstract}
Several factors can affect the water quality of cacimbas, which makes it necessary to monitor it for human consumption. In this sense, the present work sought to analyze a physical-chemical and microbiological quality of water from cacimbas in the rural area of the district of Iara, city of Barro, Ceará. The waters were collected directly from the tanks in sterile containers, then they were stored in thermal boxes with ice for conservation and transported for analysis in the laboratory. Physical-agglomerated analyzes were performed to determine turbidity, electrical conductivity, total hardness, chlorides, ammoniacal nitrogen, nitrate, nitrite, $\mathrm{pH}$, aluminum, total iron, total dissolved solids and manganese, and microbiological analyzes to determine total coliforms and Escherichia coli. The results hindered that most of the proven water of the cacimbas quality independent in relation to the physico-chemical parameters, but some changes in relation to the durability, and the nitrate and iron terrors. All samples showed microbiological
\end{abstract}

*erlanio@centec.com.br 
contamination by total coliforms and only one had no contamination by E. coli. The data reinforce the question of the susceptibility of cacimbas to various contamination factors and the need for greater measures to revert the population that cause the contamination of cacimbas.

Keywords: Water supply. Water quality. Physico-chemical and microbiological analysis.

\section{INTRODUÇÃO}

O Brasil é um país rico em recursos hídricos e parte dessa riqueza encontra-se em rios, lagos e lençóis subterrâneos. Para que pudesse utilizar a água subterrânea, o ser humano buscou desde as civilizações antigas, técnicas para extração, e hoje existem poços freáticos, poços artesianos, cacimbas, cacimbões, poços amazonas, entre outros meios (NANES e FARIAS, 2012).

Poço é uma perfuração feita no solo com objetivo de coletar água, e pode ser classificado em poços rasos ou poços profundos. Os rasos captam água do lençol freático, geralmente tem forma circular e profundidade não mais que $20 \mathrm{~m}$, podendo ser escavados, perfurados ou cavados. Os poços cavados geralmente são perfurados manualmente e possuem um diâmetro de cerca de 0,80 a $1,50 \mathrm{~m}$, alguns casos chegam a $2 \mathrm{~m}$. Esse tipo são popularmente conhecidos como cacimbões, estando em grande número no meio rural nordestino (FEITOSA e MEDEIROS FILHO, 1995).

Devido ao semiárido brasileiro ter uma baixa disponibilidade de água potável, situação que se agrava em área rural, principalmente em período de estiagem, o uso de cacimbas é um mecanismo viável (GOMES FILHO, 2013). Um exemplo é o município de Barro, situado ao sul do estado do Ceará, onde cerca de $37 \%$ das residências estão localizadas na zona rural.

\section{MATERIAIS E MÉTODOS}

\section{Área de estudo}

A cidade de Barro está situada ao Sul do estado do Ceará, inclusa na Macrorregião Cariri Centro-Sul. De acordo com dados do Instituto de Pesquisa e Estratégia Econômica do Ceará (IPECE, 2017), a população barrense foi estimada em 2010 em 21.514 habitantes.
O abastecimento de água para 17,63\% da população desse município provém de poços ou nascentes, $15,32 \%$ provém de outras fontes e $67,05 \%$ da rede de abastecimento local (IPECE, 2017).

No entanto, as cacimbas são de fácil contaminação devido a infraestrutura rústica, na maioria das vezes sem revestimento interno. A cobertura normalmente é feita de forma inadequada possibilitando contaminações externas, provenientes de enxurradas e esgoto. Além disso, o fluxo de água subterrânea pode vir a ser comprometido pela contribuição de esgoto sanitário, agrotóxicos, pesticidas, inseticidas e outros (CAMPOS, 1999).

De particular importância, a água de qualidade é essencial para evitar prejuízos à saúde da população, para isso, deve estar livre de contaminação química e biológica para evitar doenças de veiculação hídrica. Portanto, é importante que as comunidades tenham acesso a água de qualidade, por isso, faz-se necessário análises físicoquímicas e microbiológicas (MONTEIRO, 2018).

Nesse sentido, o presente estudo objetivou verificar a qualidade físicoquímica e microbiológica da água de cacimbas que são utilizadas para diversos fins em um distrito da cidade de Barro, Ceará.

O município possui 8 distritos, sendo esses: Barro, Brejinho, Cuncas, Engenho Velho, Monte Alegre, Santo Antônio, Serrota e Iara foco do presente estudo. Nem todas as famílias deste distrito são assistidas pelo sistema de abastecimento da Companhia de Água e Esgoto do Estado do Ceará. A fração de famílias que não são 
assistidas, tem seu abastecimento por cacimbas individuais e ou compartilhadas por famílias próximas.

O tipo de solo encontrado no município é o litólico e bruno não-cálcicos, havendo ainda areias quartzosas distróficas e solos podzólicos, com predominância do embasamento cristalino. O domínio hidrogeológico advém de rochas sedimentares, cristalinas e depósitos aluvionares que estão inseridos na Bacia Hidrográfica do Salgado e dispõe do Rio de Cuncas e do Riacho dos Cavalos como principais drenagens superficiais (BRASIL, 1998).

\section{Coleta das amostras}

As amostras de água foram coletadas no período da manhã diretamente nas cacimbas, somando um total de sete coletas. A seleção dos pontos para a coleta do material foi determinada de forma aleatória, visando contemplar todo o curso hídrico que corta a localidade. As coletas foram realizadas utilizando como recurso metodológico o Manual de Análises Físicoquímicas de Águas de Abastecimento e

\section{RESULTADOS E DISCUSSÃO}

\section{Análises físico-químicas}

Os resultados dos parâmetros físicoquímicos das amostras de água de cacimbas
Residuárias (SILVA e OLIVEIRA, 2001). As amostras foram coletadas em recipientes estéreis de acordo com o método utilizado e quantidade a ser coletada, codificando cada um conforme seu ponto de coleta. Em seguida, foram armazenadas em caixas térmicas com gelo para conservação e para transporte para análises em laboratório.

\section{Caracterização físico-química e microbiológica}

As análises físico-químicas da água de cacimbas foram realizadas utilizando-se as normas da Portaria 05 de 28 de setembro de 2017 do Ministério da Saúde (BRASIL, 2017). As análises foram feitas objetivando a determinação de turbidez, condutividade elétrica, dureza total, cloretos, nitrogênio amoniacal, nitrato, nitrito, $\mathrm{pH}$, alumínio, ferro total, sólidos totais dissolvidos (STD) e manganês. As análises microbiológicas de água de cacimbas foram realizadas visando a determinação de coliformes totais e Escherichia coli considerando os limites estabelecidos Portaria 05 de 28 de setembro de 2017 do Ministério da Saúde - MS (BRASIL, 2017).

do distrito de Iara, cidade de Barro Ceará, estão demonstrados na Tabela 1. 
Tabela 1 - Resultados de análises físico-químicas de água de cacimbas do distrito de Iara, cidade de Barro, Ceará.

\begin{tabular}{|c|c|c|c|c|c|c|c|c|c|}
\hline Parâmetros & Unidade & P01 & P02 & P03 & P04 & P05 & P06 & P07 & Legislação* \\
\hline $\mathrm{pH}$ & - & 7,0 & 7,1 & 7,3 & 6,7 & 6,8 & 7,3 & 6,6 & $6,0-9,5$ \\
\hline Cloretos & $\mathrm{mgCl}^{-} / \mathrm{L}$ & 10,0 & 20,5 & 18,5 & 8,0 & 35,5 & 10,0 & 24,5 & 250,0 \\
\hline Dureza & $\mathrm{mgCaCO}_{3} / \mathrm{L}$ & 150,0 & 234,0 & 120,0 & 96,0 & 192,0 & 60,0 & 110,0 & 500,0 \\
\hline Condutividade & Us/cma & 60,0 & 110,0 & 102,0 & 140,4 & 348,2 & 249,9 & 158,4 & - \\
\hline $\begin{array}{l}\text { Nitrogênio } \\
\text { amoniacal }\end{array}$ & $\mathrm{mgNH}_{3} / \mathrm{L}$ & 0,0 & 0,0 & 0,0 & 0,0 & 0,0 & 0,0 & 0,0 & 1,5 \\
\hline Nitrito & $\mathrm{mgN}^{-} \mathrm{NO}_{2}^{-} / \mathrm{L}$ & 0,0 & 0,0 & 0,0 & 0,0 & 0,1 & 0,0 & 0,0 & 1,0 \\
\hline Nitrato & $\mathrm{mgN}^{-} \mathrm{NO}_{3}^{-} / \mathrm{L}$ & 11,0 & 11,0 & 2,3 & 3,3 & 11,0 & 7,4 & 11,0 & 10,0 \\
\hline Ferro total & $\mathrm{mg} / \mathrm{L}$ & 0,0 & 0,0 & 0,5 & 0,0 & 0,0 & 0,0 & 0,0 & 0,3 \\
\hline STD & $\mathrm{mg} / \mathrm{L}$ & 308,0 & 393,0 & 241,0 & 205,0 & 385,0 & 298,0 & 197,0 & $1.000,0$ \\
\hline Turbidez & UNT & 69,0 & 113,0 & 128,0 & 71,0 & 89,0 & 76,0 & 83,0 & 5,0 \\
\hline Manganez & $\mathrm{mg} / \mathrm{L}$ & 0,0 & 0,0 & 0,0 & 0,0 & 0,0 & 0,0 & 0,0 & 0,1 \\
\hline Aluminio & $\mathrm{mgAl} / \mathrm{L}$ & 0,0 & 0,0 & 0,0 & 0,0 & 0,0 & 0,0 & 0,0 & 0,2 \\
\hline
\end{tabular}

*Portaria da Consolidação $n^{\circ} 05$ de 28 de setembro de 2017 do MS (BRASIL, 2017).

Utilizou-se a Portaria da Consolidação $\mathrm{n}^{\circ} 05$ de 28 de setembro de 2017 do MS (BRASIL, 2017) como legislação de referência, considerando os Valores Máximos Permitidos (VMP).

$\mathrm{Na}$ análise de $\mathrm{pH}$ observou-se que os resultados variaram de 6,6 a 7,3, estando as amostras de acordo com as recomendações da legislação. Os resultados foram semelhantes aos obtidos por Daneluz e Tessaro (2015), onde analisaram 45 poços rasos de propriedades rurais da região sudoeste do Paraná, e os valores de $\mathrm{pH}$ variaram de 6,1 e 8,3 .

$\mathrm{O}$ pH tem relação direta com o crescimento bacteriano e a faixa para seu desenvolvimento varia de 6,5 a 7,5 (DANELUZ e TESSARO, 2015). Água com pH abaixo de 6,0 é classificada como ácida e corrosiva e acima de 9,5 como básica, contribuindo para precipitação de sais e incrustações dos mesmos, assim o $\mathrm{pH}$ é essencial para manter em boas condições as tubulações que conduzem a água as residências (MONTERIO, 2018).

Concentrações altas de cloretos são responsáveis por deixar a água com gosto salino e podem ser originárias da falta de proteção das cacimbas ou poços rasos como são conhecidos e até por conta da distância de foças (CAPP et al., 2012). Para esse parâmetro os resultados variam de 8,0 a $35,5 \mathrm{mgCl}^{-} / \mathrm{L}$, estando em conformidade com as recomendações da legislação. Os valores obtidos estão em conformidade com a variação de cloreto observada por Saling et al. (2017), que analisaram poços rasos do município de Colinas, Rio Grande do Sul.

As amostras apresentaram valores de dureza variando de 60,0 a 234,0 mg/L, podendo ser classificadas como brandas e estão em conformidade com as recomendações da legislação. Resultado inferior para a dureza foi observado por Monteiro (2018) para água de cacimbas da cidade de Areia, Pernambuco, com valores variando de 16 a 57,3 mg/L. Essa diferença pode estar ligada ao tipo de solo e a qualidade do curso hídrico que alimenta os mananciais subterrâneos. Elevado teor de dureza influencia principalmente na capacidade de inibir o sabão de fazer espuma, dissolver óleos, graxas e gorduras (MONTEIRO, 2018).

Os valores de condutividade elétrica variaram de 60,0 a 384,2 Us/cma. A legislação usada para comparação não estabelece valores máximos para esse parâmetro, no entanto, os valores foram semelhantes aos obtidos por Saling et al. 
(2017) para poços rasos, com variação de 61,00 a 380,46 Us/cma. A água rica em matéria inorgânica é um fator para que ela apresente elevada condutividade e salinidade e tem uma tendência a aumentar em período chuvoso (GOMES FILHO, 2013; BRUM et al., 2016).

As amostras não apresentaram nitrogênio amoniacal, estando de acordo com a legislação. Por outro lado, Monteiro (2018) verificou em água de cacimbas, valores de nitrogênio amoniacal variando de 0,05 a $0,26 \mathrm{mgNH}_{3} / \mathrm{L}$. Esse parâmetro é um indicativo de poluição recente sendo lançada no curso hídrico (GOMES FILHO, 2013).

Os valores de nitrito na água das cacimbas variaram de 0,0 a $0,1 \mathrm{mg} / \mathrm{L}$, o que indica que os resultados estão de acordo com a legislação. Resultados semelhantes para nitrito foram obtidos por Costa et al. (2018) para água de cacimbas do município de Humaitá, Amazonas, com valores variaram de 0,01 até $1,0 \mathrm{mg} / \mathrm{L}$. Esse parâmetro é importante, pois concentrações altas de nitrito podem causar a metahemoglobinemia em criança recémnascidas (GOMES FILHO, 2013).

Nas amostras de água das cacimbas os valores de nitrato variação de 2,3 a 11,0 $\mathrm{mgN}^{-} \mathrm{NO}_{3}{ }^{-} / \mathrm{L}$. Foi observado que as amostras dos pontos P01, P02, P05 e P07 apresentaram valores superiores ao recomendado pela legislação. Saling et al. (2017) verificaram em amostras de água de poços rasos que a variação de nitrato foi de 0,33 a $11,11 \mathrm{mgN}^{-} \mathrm{NO}_{3}{ }^{-} / \mathrm{L}$, e que, algumas amostras demonstraram valores superior a legislação. Nitrato pode ser de origem natural vinda de rochas ígneas, do uso de fertilizantes, de áreas de drenagem e da decomposição da matéria orgânica podendo ser intensificadas por esgotos domésticos e industrial (HELLER e PÁDUA, 2010).

Os resultados obtidos nas análises de ferro na água variam de 0,0 a $0,5 \mathrm{mg} / \mathrm{L}$. A amostra que apresentou valor igual a 0,5 $\mathrm{mg} / \mathrm{L}$ está em desacordo com as recomendações da legislação que preconiza VMP de 0,3 mg/L. O ferro está mais presente em águas subterrâneas, logo são propensas a apresentar teores mais elevados. Assim sendo, podem causar corrosão e a incrustação em tubulações e também acarretar um sabor adstringente quando associado ao manganês (HELLER e PÁDUA, 2010).

Nas amostras de água das cacimbas foram verificados valores de sólidos totais dissolvidos (STD) que variaram de 197,0 a $393,0 \mathrm{mg} / \mathrm{L}$. Todas os valores estão de acordo com as recomendações da legislação. A variação observada foi inferior a obtida por Oliveira et al. (2018) para água de cacimbas, com variação de 70 a $920 \mathrm{mg} / \mathrm{L}$. Os sólidos na água podem ocorrer de forma natural oriundo de processos erosivos, organismos e detritos orgânicos ou por atuação antropogênica, destinação inadequada de lixo e esgoto (BRITO, 2019).

Os resultados apresentaram valores de turbidez nas amostras de água que variaram de 69,0 a 128,0 UNT. Pôde-se observar que nenhuma das amostras se enquadrou nas recomendações da legislação. Em um estudo similar foi observado valores que variaram de 0,30 a 40,07 UNT (BRUM et al., 2016). Os resultados foram associados ao carreamento e lixiviação das paredes das cacimbas que não possuem estruturas adequadas para manter a qualidade da água.

As amostras apresentaram ausência de manganês e alumínio, estando de acordo com as recomendações da legislação. O manganês, pode atribuir à água para consumo humano um gosto amargo e adstringente quando associado ao ferro (HELLER e PÁDUA, 2010).

\section{Análises microbiológicas}

Os resultados das análises microbiológicas das amostras de água de cacimbas estão apresentados na Tabela 2. Verificou-se a presença de coliformes totais em todas as amostras coletadas e a ausência de E. coli apenas na amostra P01. Todas as amostras águas das cacimbas estão em desacordo com a Portaria 05 de 28 de setembro de 2017 do MS (BRASIL, 2017), que sugere um padrão satisfatório a 
ausência de bactérias do grupo coliformes totais e E. coli a cada $100 \mathrm{~mL}$ da amostra. Esses resultados estão de acordo com Saling et al. (2017), que observaram presença coliformes e E. coli em amostra de água de poços rasos do município de Colinas, Rio Grande do Sul.

Tabela 2 - Resultados das análises microbiológicas de água de cacimbas do distrito de Iara, cidade de Barro, Ceará.

\begin{tabular}{ccc}
\hline Pontos de coleta & Coliformes totais & E. coli \\
\hline P01 & + & - \\
P02 & + & + \\
P03 & + & + \\
P04 & + & + \\
P05 & + & + \\
P06 & + & + \\
P07 & + & +
\end{tabular}

(+): Presença; (-): Ausência

As cacimbas são mais suscetíveis às contaminações, ao contrário dos aquíferos artesianos, que estão confinados por camadas relativamente impermeáveis, que protegem as águas de possíveis contaminações (ROSA et al., 2004). A infraestrutura rústica e as vezes sem revestimento interno e cobertura de forma inadequada, são fatores relevantes para facilitar a contaminação microbiológica de cacimbas (CAMPOS, 1999).

\section{CONCLUSÕES}

Diante dos resultados foi possível observar que a maioria das amostras de água proveniente das cacimbas apresentaram qualidade em relação aos parâmetros físicoquímicos. No entanto, a maioria das amostras apresentaram contaminação microbiológica, e que pode ser devido a

\section{REFERÊNCIAS BIBLIOGRÁFICAS}

BRANCO, S. M.; Água: origem, uso e preservação. São Paulo: Moderna, 2001.

BRASIL, 1998. República Federativa do Brasil Ministério de Minas e Energia CPRM - Serviço Geológico do Brasil Diretoria de Hidrologia e Gestão Territorial
A presença de coliformes na água é indicativo da presença de esgotos, o que, por sua vez, significa a possibilidade da presença de patogênicos (BRANCO, 2001). A E c coli é a bactéria mais representativa dentro do grupo dos coliformes termotolerantes, e sua presença é indicativa de coliformes fecais, pois é habitante do trato intestinal de humanos e animais de sangue quente (SALING et al., 2017).

vários fatores de contaminação as quais as cacimbas estão susceptíveis. Esses dados são relevantes para reforçar a temática da facilidade de contaminação das cacimbas, somado a real necessidade de maiores medidas para se rever hábitos da população que provocam a contaminação de cacimbas.

Residência de Fortaleza. Diagnóstico do Município de Barro. Fortaleza, 1998.

BRASIL, 2017. Ministério da Saúde. Portaria da Consolidação $\mathbf{n}^{\circ} 05$ de 28 de setembro de 2017. Consolidação das normas sobre as ações e os serviços de 
saúde do Sistema Único de Saúde. Ministério da Saúde. Disponível em: https://portalarquivos2.saude.gov.br/image s/pdf/2018/marco/29/PRC-5-Portaria-de-

Consolida----o-n---5--de-28-de-setembrode-2017.pdf. Acesso em 23 de fevereiro de 2020.

BRITO, K. P. Qualidade da água de poços artesianos das comunidades rurais Aroeiras e Pau Ferro em São José de Piranhas-PB. Cajazeiras, 2019. Disponível em:

http://dspace.sti.ufcg.edu.br:8080/jspui/bits tream/riufcg/11002/1/KILDERY\%20PED ROSA\%20DE\%20BRITO.\%20TCC.\%20L ICENCIATURA\%20EM\%20QUÍMICA.\% 202019.pdf. Acesso em: 27 de janeiro de 2020.

BRUM, B. R.; OLIVEIRA, N. R.; REIS, H. C. O.; LIMA, M.; MORAIS, E. B. Qualidade das águas de poços rasos em área com déficit de saneamento básico em Cuiabá, MT: avaliação microbiológica, físico-química e fatores de risco à saúde. Holos. v. 2(32): 179-188, 2016.

CAMPOS, J. G. V. Contaminação das Água Subterrâneas na Cidade de Mirante da Serra (RO), 1999, CPRM Serviço Geológico do Brasil Superintendência Regional de Salvado BA; disponível em: https://aguassubterraneas.abas.org/asubterr aneas/article/view/23418/15503; acesso em 05 de dezembro de 2019.

CAPP, N.; AYACH, L. R.; SANTOS, T. M. B.; GUIMARÃES, S. T.L. Qualidade da água e fatores de contaminação de poços rasos na área urbana de Anastácio (MS). Geogra a Ensino \& Pesquisa, v. 16(3): 2012.

COSTA, T. A. C. R.; OLIVEIRA, B. O. S.; VALENTE, K. S. Avaliação da qualidade de águas de poços cacimbas e rasos no município de Humaitá-AM. Revista EDUCAmazônia - Educação Sociedade e Meio Ambiente. v. XX(1): p. 157-172, 2018.

DANELUZ, D.; TESSARO D. Padrão físico-químico e microbiológico da água de nascentes e poços rasos de propriedades rurais da região sudoeste do Paraná. Dois Vizinhos - PR, 2014. Disponivel em: https://www.scielo.br/pdf/aib/v82/18081657-aib-1808-1657000072013.pdf.

Acesso em: 19 de novembro de 2020.

FEITOSA N. B. e MEDEIROS FILHO, C. F. Abastecimento de Água no Meio Rural-Treinamento de Curta Duração Saneamento Rural (Abastecimento D’Água). Campina Grande - PB, 1995 Disponivel em: http://www.dec.ufcg.edu.br/saneamento/A 0. html?submit=Voltar+ao+\%CDndice;

Acesso em 10 de fevereiro de 2020.

GOMES FILHO, R. R. (org), Gestão de Recursos Hídricos: conceitos de experiências em bacias hidrográficas. 1. ed. - Goiania: Grafica e Editora América, e co-edição com a Editora da UEG, 2013.

HELLER, L. e PÁDUA V. L. de, (org), Abastecimento de Água para Consumo Humano, $2^{\mathrm{a}}$ edição revisada e atual, Belo Horizonte - MG, editora UFMG, 2010, 1 v: il, (ingenium).

IPECE - Instiuto de Pesquisa e Estratégia Econômica do Ceará - Barro, 2017. Disponível em: < http://www.ipece.ce.gov.br/perfil_basico municipal/2015/Barro.pdf. Acesso em: 13 de janeiro de 2020.

MONTEIRO, G. F. Análises físicoquímicas das águas de poços tipo cacimba na cidade de Areia - PB, 2018. Areia - PB; Disponível em: https://repositorio.ufpb.br/jspui/bitstream/1 23456789/11100/1/GFM03082018.pdf;

Acesso em 20 de janeiro de 2020.

NANES, D. P. e FARIAS S. E. M. Qualidade das Águas Subterrâneas de Poços Tipo Cacimba: um Estudo de Caso da Comunidade Nascença - Município de São Sebastião - Al.(*), São Sebastião - Al, $2012 . \quad$ Disponível em: http://www.ibeas.org.br/congresso/Trabalh os2012/VIII-024.pdf. Acesso em $07 \mathrm{de}$ fevereiro de 2020. 
OLIVEIRA, V. R. Impactos das tecnologias nas ciências exatas e da terra. Organização Atena Editora. - Ponta Grossa: Atena Editora, 2018.

ROSA, C. C. B.; ALMEIDA, F. T.; SANTOS JÚNIOR, E. L.; ALVES, M. G.; MARTINS, M. L. L. Qualidade microbiológica de água de poços provenientes de áreas urbanas e rurais de Campos dos Goytacazes (RJ). In: XIII Congresso Brasileiro de Águas Subterrâneas Anais. Cuiabá/MT, 2004.

SALING, C.; GRAFF, A.; ENIZ, E. C.; BOCKEL, W. J. Avaliação da qualidade da água de poços rasos no município de colinas - RS. Tecnológica, v. 21, n. 2, p. 59-64, 2017.

SILVA, S. A. OLIVEIRA, R. Manual de Análises Físico-Químicas de Águas de Abastecimento e Residuárias, 2001. Campina grande - PB. 